\title{
Censorship as a human dynamic: an international perspective
}

\author{
SARA FINE \\ Dept. of Library Science, Library and Information Science, \\ University of Pittsburgh, PA 15260, email: fine@LIS.pitt.edu
}

\begin{abstract}
By their very nature, democracies around the world affirm belief in intellectual freedom of thought, speech and the written word. In every such society, however, a counterforce exists that would limit such freedom and impose restrictions and sanctions against material viewed by some as anti-moral or anti-social. Free speech and censorship are opponents on a battlefield where each side to the conflict feels a righteous and indignant claim on behalf of its own cause.

This paper presents a psychological perspective which tries to understand censorship-where it comes from, who "has it" and why, and how it functions in all human beings to keep them psychologically safe and sane.

Based on personality theory, this paper explores the psychological indications for censorship as a human dynamic and its bases in family ideology, social group noms, demographic factors and individual personality development. This paper does not consider the legal, moral or political aspects of censorship, nor does it recount the many blatant subtle censorship events and conditions in countries around the world. Rather, it considers the individual and group conditions underlying personality development that are likely to result in the individual's inclination to assume legal, moral and political censorship activities.
\end{abstract}

\section{Introduction}

Ray Bradbury's Fahrenheit 451 was celebrated recently upon reaching its 40th anniversary-a still remarkable book that is well worth revisiting today. Despite its story of a society where books were abhorred, outlawed, and ritually burned, the book isn't really about censorship. It is about how human beings think and feel about knowledge. It is about how the need for love and affiliation affects whether we yield or whether we fight when our right to information is denied us. It is about how deeply social pressure affects what we believe and what we will defend. Bradbury's book is about the relationship between censorship and risk taking. Mostly it is about apathy, compliance, habit, and ritualistic thinking. It is about how easy it is for human beings to believe the inner voice that says, "If you don't see it, read about it, let yourself be aware of it- then it doesn't exist." There's a price for free speech. We always have to balance our right to free speech against the fires of opposing passion that it can light, the pain it can cause, and the divisions it can open up.

Education for All: Culture, Reading and Information, IASL, 1998 
By their very nature, democracies around the world affirm belief in intellectual freedom of thought, speech, and the written word. In every democratic society, however, a counter force exists that would limit such freedom and impose restrictions and sanctions against material viewed by some of its members as anti-moral or anti-social. Between countries, the issues of censorship and the transborder flow of information affect foreign policy decisions and the resulting international relationships. Free speech and censorship are opponents on a battlefield where each side to the conflict feels a righteous and indignant clain on behalf of its own beliefs and contentions. Censorship, then, is a crucial manifestation of personality within societies and between societies.

The purpose of our gathering at the International Association of School Librarianship in Tel Aviv was to come together for a moment in time to view our personal, local, idiosyncratic concerns from a broader perspective-from a global perspective-and to enhance and enrich our own narrow and limited visions by infusing them with cultural and cross cultural seasonings. The author's intent in this paper is to move from an earlier work on the issue of censorship as an individual psychological dynamic to a broader and more seasoned international perspective.

\section{Background of this paper}

In an earlier article (Fine, 1997), the author explored the human dynamic of censorship in terms of its psychological dimensions. The purpose of this current article is to take some principles from individual personality and group dynamics theories described in that earlier article and expand those principles to the personality and censoring behavior of different countries. While in every society there are obviously differences and dissension among individual members, the assumption here is that every country holds a general set of beliefs and shares a general set of behaviors that in psychological terms, could be called a national personality. We are really talking of a national personality when we say, "What will China do next?" or "How will Iraq respond?" or "How does Kuwait view the role of women?" When we consider our expectations about how a country will behave, we are really reflecting our perception of that country's personality. It is from this national character that censorship behavior evolves, just as it evolves in an individual from personality traits intermingled with personal history and the prevailing social norms.

In pursuing an understanding of censorship, it is difficult to separate issues of personal freedom from issues of freedom of expression. They are so obviously interconnected that separation may be impossible. So while the purpose of this paper is to explore the dynamics of nationally imposed and condoned censorship, spillover to other issues and motives is inevitable.

\section{The individual personality of censorship}

From what we know of individual personality theory, it is possible to create a demographic and behavioral profile of the Censor. While the person described here probably doesn't really exist in this pure form, there are some demographics and behaviors that can characteristically be ascribed to the Censor. Perhaps if we understand a little more about the censoring personality and recognize its psychological bases, our own reactions and behavior in dealing with censorship would be more effective. 
Here is a portrait of the Censor. His name is probably familiar to us because of his propensity for writing letters of protest, marching in rallies, and making speeches at Board of Directors' meetings. He probably grew up in a small town or on a farm and moved to the city as a young man looking to improve his life. He's now in his mid-forties. He is married to his childhood sweetheart and is the father of four children; he had two years of college and then quit; he is a loyal member of some fraternal order-in fact, belonging to a group of people like himself is very important to him; he's an active church-goer and is considered a "good family man." His upbringing was probably strict and the rod was not spared. In fact, he probably believes in spanking his children when they misbehave. He is strongly vocal against sex or AIDS education in the schools and he's against teaching the theory of evolution to children. It's always a challenge to argue with him. We keep hoping he will open his mind, and he doesn't. We just keep hoping he'll go away-and he doesn't.

\section{The national personality of censorship}

The profile of the censor can extend beyond itself and invade a whole country, thereby informing the national personality (Inkeles, 1997). Censorship is manifested nationally by any number of policies, attitudes and behaviors. In most cases, governmental controls and legal restrictions on certain kinds of materials are blatant expressions of the national personality.

But there are a variety of other ways that nations have contrived to control ideas. A more subtle form of censorship is reflected in the way a government determines where it spends money. Lack of support for public libraries or a tacit acceptance of illiteracy, for example, may not be economic decisions but psychologically motivated acts of censorship.

Another manifestation of this national personality dynamic is the pressure that individual citizens are expected to exert on their fellow members who do not conform to accepted rules of behavior and beliefs. Compliance appears to be voluntary, but non-conformity is treated with prescribed harshness by neighbors, friends, and often by a loving family.

A very powerful manifestation of the collective censoring personality is a national call to arms: members of the society are convinced of the existence of a real or imagined enemy, convinced that they must be alert to protecting themselves from destruction. Where an enemy exists, even if imaginary or even if created for the purpose of thought control, censorship becomes an acceptable-even desirable-means of self preservation. Most members of a society willingly accept the requirement to sacrifice their right to information on the altar of national security.

Perhaps the most potent symptom of a national censoring personality is denial of reality, where an entire population comes to believe that something does not exist (Habiby, 1988). One example of denial can be found in maps and school textbooks where whole countries are wiped out of consciousness by simply not including the information of their existence. In some countries it is prohibited to say that the president has a lover, even when everyone in the country knows it to be a fact (a certain indication that the United States does not have a collective censoring personality). In those same countries it is usually prohibited to speak poorly of the military. In other countries where there are strict religious taboos, for example, against the pig, books on animals routinely have the section where pigs are 
described removed from the book-and therefore the pig doesn't exist. Denial is a very potent form of thought control.

Censoring behavior whether by an individual, a group or a nation-is generally irrational and frustrating, yet we often respond to it by logic and reasoning, as though it were changeable by rational argument. Yet we know that it isn't. It may be useful, therefore, to try to understand this behavior not from a political or an argumentative point of view but from a psychological perspective. Some of the principles of human behavior may give us insight into the notion of a "national personality" that manifests itself in censorship behavior. These principles were evolved from the following theories: the nature and evolution of the authoritarian personality by Adorno (1993) and others (Robinson, 1995; Smith, 1997); the relationship of group behavior to censorship based on Janis' (1972) "Groupthink Hypothesis;" Kohlberg's (1981) studies of stages and levels of moral development; Festinger's (1957) concept of cognitive dissonance and attitude formation; and related theories on dogmatism, religiosity, and values (Bilsky and Schwartz, 1994; Davies, 1993; Peterson, 1997; and Stiehler, 1991).

\section{Psychological principles from personality theory}

Where does censorship come from, and what is its meaning in the collective human experience? What purpose does it serve, and how does it work to keep us feeling safe and sane. Why do some individuals-and some countries-"have it" while others don't?

On some level, the National Censor and an Individual's Censor perform the same function. The National Censor's motive is to preserve the society from self-destruction. Even in the most liberal country, not everything is acceptable to be said or written. Even in the freest of societies our national self interest promotes some form of censorship. It is in our human nature as individuals and as social creatures that each of us has a Censor inside ourselves. If we look at some of the principles of human behavior, the purpose of censorship and its function in our lives becomes clearer.

First Principle. We all "have it." We must have an internal censor to keep us healthy, safe and moral. A Censor lives in each of us, keeping our darker impulses under cover. Without it we would run wild, screaming obscenities, committing murder and mayhem, performing private acts in public. Our internal censor is what makes us civilized.

The problem is that sometimes the Censor inside turns outward and tries to control not only ourselves, but others as well. Sometimes the Censor protecting our national security goes beyond the bounds of its purpose and tries to extend its power. When the National Censor turns outward to inflict itself on its neighboring countries, we end up with an old-fashioned "personality conflict" among nations, a prelude to aggression.

Second Principle. Personality theory and social psychology research suggest that the characteristic attitudes and behavior of the Censor indicate an authoritarian personality. It isn't hard to relate the concept of authoritarianism to the personality of certain countries.

When we try to understand the authoritarian, the first assumption we make is that he is afraid of something. Whether the fear is based on some real threat or an exaggeration of some mild danger or an unconscious reaction to some deep and hidden black impulse is 
not important. The important issue is that the authoritarian is reacting to something he fears.

Being afraid of a real threat and securing against it is a perfectly rational act of human self preservation. The problem, both with individuals and with countries, is that the threat is often ambiguous and unclear. It is mixed up with emotion, with unresolved historical angers and outrages, with unfounded beliefs, with unspoken and perhaps unconscious other fears. Threat has a way of feeding on itself-that is, to be threatened is to behave defensively which often arouses aggression which produces more threat... The unfortunate spin-off is that the feelings of threat are so convoluted that they cannot be reasoned or argued away. The feelings of threat are too real and no country can risk ignoring them. When something threatens us we resist, we defend, we rationalize, we fight, we censor. So censorship is often a defense mechanism against some psychological threat.

Third Principle. Power issues are often the psychological motivation for censorship. Let's look a little deeper. The authoritarian has great need to control, to exert power; that's obvious. But it is not that simple. The authoritarian personality also has an equally strong need to submit to power. The classic example of the authoritarian personality is the stereotypical Nazi who is both authoritarian and profoundly submissive to authority, who with deep conviction justifies his acts of brutal power as "only doing what he was commanded to do." And it is not just an excuse; he means it. To make matters more complicated, underneath the facade of self-righteousness and aggressiveness on the one hand and submission to a higher authority on the other hand, there is a third dynamic. The authoritarian has a deep resentment against his own feelings of weakness, a resentment that often comes out in hostility and aggression against people he sees as deviants, or inferiors, or weaklings. The authoritarian is both controlling and subnissive-and expresses this ambivalence, this contradiction, against those he has decided are lesser human beings. Does this sound like some countries we can think of?

So the authoritarian personality, whether an individual or a country, is rigid, moralistic and aggressively defensive of beliefs, has a great need to control and at the same time is submissive to authority, and is angry at its own weakness.

Fourth Principle. The authoritarian is most comfortable with the certainty that things are black or white, evil or good, clean or dirty, legal or illegal. Ambiguity is unsettling and unbalancing. In order to maintain balance, the authoritarian takes on a kind of mental handrail to hold on to and believe in. The problem is that the "handrail" often comes out as racism, sexism, ethnocentricity, militarism, and anti-Semitism. These prejudices are harsh enough when they belong to an individual-but when a whole society or country collectively takes them on, the consequences can be devastating.

Fifth Principle. It will probably come as no surprise that studies of authoritarianism, rigidity and dogmatism have consistently shown a strong relationship between church-going and authoritarianism. I am not suggesting a causal relationship. Being religious does not make one dogmatic; there are religious people and countries with a state religion that are not dogmatic; one does not have to be religious to be dogmatic. But dogmatics and authoritarians look for solid dogma and a higher authority; they often find them through religion, particularly fundamentalist religions. Sometimes authoritarians will follow a mortal leader, but they will often elevate and cloak him in an aura of divinity. After all, belief in a divine authority reduces the ambiguity of life. Such belief provides serious rules and 
guidelines and a morally inspired path to follow. If the real threat comes from ambiguity, what better way is there to maintain balance than to follow divine dogma? A fundamentalist religious country allows for little ambiguity, and censorship is not so much an act as a way of life.

Sixth Principle. The censoring personality seems inevitably to hold to Traditional Family Ideology with its attendant beliefs. For example:

Woman's place is in the home and her role is to please her husband;

Children should not achieve independence of thought or action;

Alternative life styles are not acceptable;

To be an outsider or to deviate from family tradition is to be morally inferior;

There is strong moral value placed on such virtues as cleanliness, hard work and thrift, honesty and devout respectability, absolute loyalty to one's own kin;

To be traditional is a virtue, to deviate is a sin;

To bring shame to the family is unforgivable;

A person's own impure thoughts-about sex for example-must be self-censored.

It is not by accident nor is it a surprise that groups trying to impose censorship in schools and public libraries, and to fight the American Library Association's firmly held position again censorship of any kind, call themselves by such names as Family Friendly Libraries, the American Family Association, Focus on the Family, and Citizens for Community Values. These groups proclaim themselves to be advocates for conservative Judeo-Christian values and ideas and enemies of anyone whose words or actions, they believe, might undermine this social worldview. The implications are clear: to be opposed to censorship by association is to be hostile to family values, to be family "unfriendly."

Related to issues of Traditional Family Values is the role of women in relation to power and authority (Magis, 1995). Women in authoritarian societies express their power urges more by sweet submission to authority and by identifying themselves with power rather than by overt aggression. In other words, they marry power. The issue, however, is still power. If we look at censorship not as a contlict of values but as a way to assert power, then censorship, particularly when it comes to our children, is not about their moral development; it is about the fear of losing control over them. Authoritarian parents are often more outraged by books that portray young people defying their parents' values than by the language the book contains-even though it is the language that will be the manifest focus of the protest. "Dirty" language is still cleaner than rebellion.

Also related to the issue of tradition and families is that the authoritarian personality, whether as an individual or a country, has a morbid fascination with and abhorrence of sex. The censor would never admit it but if he fits the profile, he has a very active imagination. He therefore sees it as his moral imperative to control not only his own impulses, but to expand his influence to those around him. It is a brilliant psychological ploy for having his cake and eating it-for keeping his human needs in balance with the imperatives of his personality. We can see how these beliets often define the personality of a whole country. 
One More Principle. The authoritarian personality is superstitious. Through superstition he controls primitive forces and weaves a mystique of his own strength and a cult of hatred for outsiders. As we have seen in human history, mysticism and superstition, prejudice and aggression are often intertwined. How many dictators have looked to the stars in planning their attacks? How many of them have been followers of the occult? How many of them have cast the die or read omens before going into battle? And has not this tendency of a leader infected the personality of the country he leads?

\section{Principles from group behavior theory}

In order to understand the national personality of censorship more deeply, we need to be aware of the dynamics of authoritarian groups. The social psychologist Irving Janis gave us a powerful description of those dynamics in his work on the 'Croupthink Hypothesis.' The parallel between groups and countries rests on the premise that conforming to the rules of the culture in which we find ourselves is much more pleasurable than dissenting from it. In other words, a more cohesive the group, the more likely it is to engage in "groupthink." Groups and countries who are committed to conformity fall into a set of behaviors whose purpose it is to reinforce that conformity and comfort. Here are some of the beliefs of groups or countries who have a need to maintain cohesiveness and conform ity:

First, they believe that they are invulnerable, even in the face of evidence that tells them otherwise. It is the belief that if we stand firmly together, nothing bad will happen to us. We see this kind of attitude in street gangs as well as in gangster governments.

Second, stereotypes about other people or other countries, the "outsiders," are shared by the members and magnified. Members accept the group's collective stereotypes as truth so that a country will convince itself that another country is immoral, weak, or inferior-that it can and should be wiped out. We see this especially in wartime where propaganda creates an enemy that is an exaggerated stereotype, sometimes even a caricature.

Third, members of the group or citizens of the country don't challenge authority, not necessarily out of fear of overt punishment. Members and citizens tend to censor their own thoughts - and to censor their thoughts about their own thoughts in order to maintain their comfort in the group. Self censorship is a powerful, invisible force in authoritarian societies, and for good reason. The authoritarian society deals harshly with dissenters, so members don't even think original thoughts, much less speak them. Members learn very quickly that direct pressure will be applied to deviant people who voice even timid disagreement.

Fourth, the authoritarian group believes that all its member are unanimous in everything. If a member feels dissension, he believes he is alone in that feeling. It seems that everyone else is in total agreement and if he voices dissent, he will be a lone voice in the wilderness.

Fifth, in countries and groups with a censoring personality there is a system of mind guards. Just as body guards protect the group and armies protect their country from physical harm, mind guards protect the group by keeping out information that is contrary to the group's beliefs, stereotypes and rationalizations. That is exactly the role of the censor: to act as a mind guard, protecting society from the "negative" influences of other countries (usually, Westernized countries). 
Sixth, perhaps the most dangerous illusion of all is the group's belief in its own morality. 'If we all agree, it can't be wrong. If we all agree, it must be moral.' The illusions of morality is the most powerful force operating in authoritarian groups and countries.

When these symptoms of "groupthink" are present in a group, the cost is high. The group's decisions are not based on reason and reality but on the collective irrationality of the group's beliefs. When countries engage in "groupthink," its decisions can have devastating consequences. Irving lanis applied his groupthink hypothesis to faulty decision-making that led the United States to what he called "foreign policy fiascos;" for example, the decision to invade the Bay of Pigs in Cuba, a flawed decision and an ill-fated adventure that resulted in humiliation and defeat; or the decision to cross the 38th Parallel in Korea despite a clear message that the act would amount to a declaration of war; or the belief that we could win a ground war in Vietnam. How could so many smart people have made such bad decisions? If we look at some of the decisions of our own countries today, we might come to the same interpretations.

\section{Conclusion}

When we understand that in dealing with censorship, we are really dealing with a deep seated personality characteristic, we also realize that much of what we do to confront censorship doesn't work. Reasoning, arguing, debating don't work. Lecturing, intellectualizing, moralizing, issuing regulations and writing procedures, even quoting Scriptures-they don't work for very long either (Benjamin, 1981; Cormier, 1991). We also realize that in our complex political environments, both within our individual countries and between countries, the voice of the censor will never be still. Censorship, like resistance and defensiveness, is one weapon in our psychological armory that is activated when something we believe we need or value is at risk.

So we are left with only one countermove-to negotiate. The principles of negotiation require several very difficult processes. First is self-awareness and the understanding that refusal to listen and engage in dialogue may come out of our own fears and dogmatism. Second is the ability to listen. In order to deal with the fears and dogma of others we must be able to quiet our own sense of outrage and moralism and hear what really lies beneath the loud voice of the censor. These are the skills we must bring to the negotiating table if we are ever to truly confront censorship at its core.

The best environment for intellectual freedom to flourish is free of psychological fear. I would conclude with a quote from John F. Kennedy on the ideal of a nation free of fear of itself:

We are not afraid to entrust the American people with unpleasant

facts, foreign ideas, alien philosophies, and competitive values.

For a nation that is afraid to let its people judge the truth

and falsehood in an open market is a nation that is afraid of

its people. 


\section{References}

Adorno, T.W. (1993). The authoritarian personality. New York: Norton.

Benjamin, A. (1981). The helping interview. Boston: Houghton Mifflin.

Bilsky, W. \& Schwartz, S.H. (1994). Values and personality. European Journal of Personality, 8(3), 163.

Cormier, W.H. (1991). Interviewing strategies for helpers: Fundamental skills and cognitive Behavioral Interventions (3rd Edition). Pacific Grove, CA: Brooks/Cole.

Davies, M.F. (1993). Dogmatism and the persistence of discredited beliefs. Personality and Social Psychology Bulletin, 19(6), 692-699.

Festinger, L.A. (1957). Theory of cognitive dissonance. Stanford, CA: Stanford University Press.

Fine, S. (1997). How the mind of the censor works. School Library Journal, January, 23-27.

Habiby, R. (1988). Teaching political science in the Arab world. Paper presented at the Annual Meeting of the Southwestern Social Science Association.

Inkeles, A. (1997). National character: A psycho-social perspective; New Brunswick, NJ: Transaction publishers.

Janis, I.L. (1972). Victims of groupthink: A psychological study of foreign policy decisions and fiascoes. Boston: Houghton Mifflin.

Kohlberg, L. (1981). Philosophy of moral development: Moral stages and the ideas of justice. San Francisco: Harper \& Row.

Magis, M.S. (1995). Religious beliefs, dogmatism, and attitudes towards women. Journal of Psychology and Christianity, 14(1), pp????

Peterson, B.E. (1997). Generativity and authoritarianism: Implications for personality, political involvement, and parenting. Journal of Personality and Psychology, $72(5), 1202-1216$.

Robinson, C.C. et al. (1995). Authoritative, authoritarian, and permissive parenting practices: Development of a new measure. Psychological Reports, 77(3), 819-830.

Smith, M.B. (1997). Authoritarian personality: A re-review 46 years later. Political Psychology, 18(1), 159-163.

Stiehler, N.J. (1991). Attitude and personality characteristics of conservative and mainline/liberal church congregations. Doctoral Thesis: Central Michigan University. 